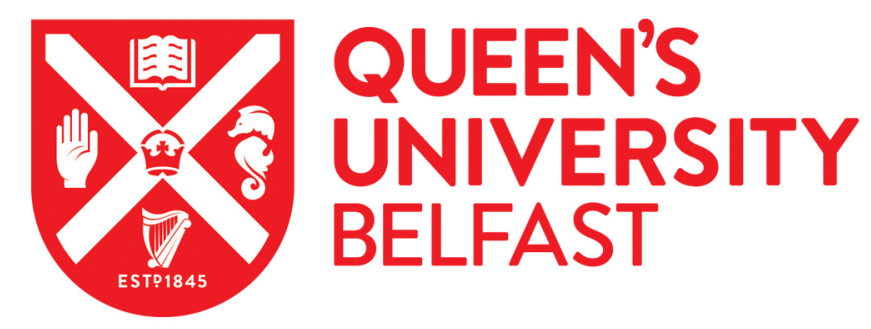

\title{
Challenges in molecular testing in non-small-cell lung cancer patients with advanced disease
}

Hiley, C. T., Le Quesne, J., Santis, G., Sharpe, R., de Castro, D. G., Middleton, G., \& Swanton, C. (2016). Challenges in molecular testing in non-small-cell lung cancer patients with advanced disease. Lancet, 388(10048), 1002-11. https://doi.org/10.1016/S0140-6736(16)31340-X

\section{Published in:}

Lancet

\section{Document Version:}

Peer reviewed version

Queen's University Belfast - Research Portal:

Link to publication record in Queen's University Belfast Research Portal

\section{Publisher rights}

(c) Elsevier Ltd. This manuscript version is made available under the CC-BY-NC-ND 4.0 license http://creativecommons.org/licenses/by-nc$\mathrm{nd} / 4.0 /$ which permits distribution and reproduction for non-commercial purposes, provided the author and source are cited.

\section{General rights}

Copyright for the publications made accessible via the Queen's University Belfast Research Portal is retained by the author(s) and / or other copyright owners and it is a condition of accessing these publications that users recognise and abide by the legal requirements associated with these rights.

Take down policy

The Research Portal is Queen's institutional repository that provides access to Queen's research output. Every effort has been made to ensure that content in the Research Portal does not infringe any person's rights, or applicable UK laws. If you discover content in the Research Portal that you believe breaches copyright or violates any law, please contact openaccess@qub.ac.uk. 
1 Challenges in molecular testing in non-small cell lung cancer patients with advanced disease

Crispin T Hiley ${ }^{1,2}$, John Le Quesne ${ }^{3}$, George Santis ${ }^{4}$, Rowena Sharpe ${ }^{5}$, David Gonzalez de Castro $^{6,7}$, Gary Middleton ${ }^{8,9}$ and Charles Swanton ${ }^{1,10}$.

1. Translational Cancer Therapeutics Laboratory, The Francis Crick Institute, London, UK.

8 2. Division of Cancer Studies, King's College London, London, UK.

9 3. Department of Cancer Studies, University of Leicester, Leicester, UK.

10 4. Department of Respiratory Medicine and Allergy, Kings College London, UK.

11 5. Cancer Research UK, London, UK.

12 6. Centre for Molecular Pathology, Royal Marsden Hospital, Sutton, UK.

13 7. School of Medicine, Dentistry and Biomedical Sciences, Queens University Belfast, UK.

14 8. Institute of Immunology and Immunotherapy, University of Birmingham, Birmingham, 15 UK.

16 9. University Hospital Birmingham NHS Foundation Trust, Queen Elizabeth Hospital, Birmingham, UK.

10. CRUK Lung Cancer Centre of Excellence, UCL Cancer Institute, London, UK.

*Correspondence to: Professor Charles Swanton. The Francis Crick Institute, 44 Lincolns Inn Field. WC2A 3LY. charles.swanton@crick.ac.uk

Summary:

24 Lung cancer diagnostics have evolved significantly in the previous decade. The challenge of molecular testing to identify an increasing number of potentially clinically actionable genetic variants, using smaller samples obtained via minimally invasive techniques, is significant. Tumour heterogeneity and cancer evolution in response to therapy means that repeat biopsies or circulating biomarkers are likely to be increasingly useful to adapt treatment as resistance develops. We highlight some of the current challenges faced in clinical practice for molecular testing of EGFR, ALK and new biomarkers such as PDL1. Implementation of next generation sequencing (NGS) platforms for molecular diagnostics in non-small cell lung cancer is increasingly common allowing testing of multiple genetic variants from a single sample. The use of NGS to recruit to molecularly stratified clinical trials is discussed in the context of the UK Stratified Medicine Programme and The UK National Lung Matrix Trial. 
Historical overview of lung cancer diagnostics

Lung cancer is the most common cause of mortality in the UK, accounting for 1 in 5 of all cancer deaths. ${ }^{(1)}$ With the estimated global incidence in 2012 of 1.83 million cases it is important to reflect that a century ago, lung cancer diagnosis was a rare event. In comparison to the current epidemic, in 1912 Isaac Adler's collection of 374 case reports in his publication Primary Malignant Growths of the Lungs and Bronchi represented the entire known global incidence at the time. A century later the WHO histological classification of malignant epithelial tumours of the lung recognizes different histologies with many variants for each subtype and analyses from next generation sequencing (NGS) studies have divided this disease into molecular subtypes defined by distinct somatic alterations. ${ }^{(2-4)}$ This review will focus on key challenges faced in current clinical practice for molecular testing in nonsmall cell lung cancer (NSCLC). In broad terms the challenges are technical, logistical and related to tumour biology and some of the pertinent issues are highlighted (Figure 1).

\section{Identification of tumour histology}

52

Historically the treatment focus for those with advanced NSCLC was selection of an appropriate cytotoxic chemotherapy regimen irrespective of histological subtype. Several large studies were published that showed the efficacy of various platinum doublet combinations were comparable but with differing drug specific toxicities. ${ }^{(5-7)}$ However accurate classification of NSCLC subtype has become fundamental in the management of advanced NSCLC following the results of phase III clinical trials showing improved progression free survival in EGFR mutation positive adenocarcinoma treated with EGFR tyrosine kinase inhibitors (TKI), ${ }^{(8,9)}$ and improved overall survival with pemetrexed in the first line and maintenance setting for those with non-squamous histology. ${ }^{(10)(11)}$

${ }^{(12,13)}$ The number of tumours that cannot be given an accurate histological diagnosis (i.e. adenocarcinoma versus squamous cell carcinoma) has reduced significantly with the use of immunohistochemical markers. The use of markers for p63, p40 and cytokeratin CK 5/6 help to identify squamous cell carcinomas, while thyroid transcription factor 1 (TTF1), Napsin A and CK7, as well as mucin stains, are indicative of adenocarcinomas. ${ }^{(14)}$ However interpretation of immunohistochemistry panels still requires the expertise of an experienced histopathologist, as markers are not reliable in isolation. ${ }^{(15)}$ TTF1 for example, a marker 
synonymous with adenocarcinoma, is expressed in only $80-90 \%$ of cases and is commonly expressed in neuroendocrine tumours. ${ }^{(14,16)}$ Immunohistochemistry can only be meaningfully interpreted in a detailed morphological context.

\section{Sampling challenges in advanced NSCLC}

The analysis of lung cancer tissue is particularly challenging as primary lung tumours often show much lower tumour cellularity than other tumour types. Even with macroscopic selection of areas of frank carcinoma the tumour purity (the fraction of a given region containing tumour cells) can often be $<20 \%$ because of the high proportion of stromal cells, lymphocytic infiltration and necrosis (unpublished observations from the UK Lung TRACERX longitudinal cohort study). ${ }^{(17)}$.

This challenge is compounded by the nature of the specimen types routinely received by histopathology and molecular diagnostics laboratories. Presentation with metastatic disease is common and only a small proportion of patients with NSCLC undergo curative surgical resection. ${ }^{(18)}$ The large tissue samples obtained via open thoracotomy (wedge resection, lobectomy, pneumonectomy) are usually of sufficient quantity and quality for a number of histological and molecular assays if handled appropriately. However patients with advanced disease are predominately diagnosed with CT guided percutaneous or US guided endoscopic biopsy with 18 gauge needles or with fine needle aspiration. These patients are the cohort where molecular diagnostics are most important for determining the standard of care and enabling participation in clinical trials yet the sample quality and quantity from such needle biopsies is the most limiting for histological and molecular testing.

Obtaining adequate tissue for diagnosis, tissue sub-typing, molecular profiling and treatment planning are therefore key to patient management. The target tumour is not always easily accessible in patients presenting with a probable lung cancer. The development of endobronchial ultrasound transbronchial needle aspiration (EBUS-TBNA) is proving increasingly important in the investigation and management of thoracic malignancies as it offers a minimally invasive approach to sampling of mediastinal lymph nodes and masses. EBUS-TBNA is now increasingly embedded in routine clinical practice with wider use beyond high volume tertiary centres in the UK and USA. It is now generally accepted that EBUSTBNA alone or in combination with endoscopic ultrasound fine needle aspiration (EUS-FNA) can potentially spare surgical mediastinoscopy or thoracotomy in the staging of NSCLC. ${ }^{(19,20)}$ 
105 Importantly, EBUS-TBNA also offers the possibility of combining diagnosis and staging as a 106 single procedure in patients with suspected lung cancer. In contrast to tissue biopsies or 107 surgical samples that allow sub-typing (adenocarcinoma versus squamous cell carcinoma) on 108 morphological criteria alone in the majority of cases, evaluation of cytological specimens 109 obtained by EBUS-TBNA poses additional challenges that can be partly overcome with wider 110 use of immunohistochemistry. ${ }^{(21)}$

112 Identifying driver mutations, such as EGFR and ALK, in these small samples is central to 113 management of patients with advanced disease. Whether molecular analysis is successfully 114 performed depends on the absolute number of tumour cells, the proportion of tumour cells 115 compared to total nucleated cells present and the method used for molecular analysis. In 116 case of EBUS-derived samples, there is evidence to conclude that simple mutation analysis 117 (EGFR, KRAS, ALK) can be successfully performed in most cases. ${ }^{(22-24)}$ The use of multi-gene 118 targeted NGS panels, using only nanograms of DNA, to sequence fine needle aspiration 119 samples is achievable and is becoming more commonly used in clinical practice. ${ }^{(25,26)}$ Whole 120 exome sequencing (WES) and whole genome sequencing (WGS) analysis which require 121 greater amounts of DNA, micrograms in the case of WGS, will be more challenging from 122 EBUS-TBNA samples.

Current challenges in molecular diagnostics for EGFR mutation analysis in clinical practice

127 The initial randomised phase II studies of gefitinib demonstrated clinical activity, ${ }^{(27,28)}$ and 128 phase III studies although negative for the primary outcome measure, suggested a benefit in 129 patients with adenocarcinoma, those of Asian origin and never smokers. ${ }^{(29,30)}$ During this 130 period a number of seminal case series identified EGFR mutations as a marker of sensitivity 131 to EGFR TKIs, ${ }^{(31-33)}$ and analysis of samples from these early trials supported this. ${ }^{(34)}$ 132 Subsequent phase III trials have incorporated EGFR mutation status and showed higher 133 response rates and progression free survival (PFS) in patients with EGFR activating somatic 134 mutations treated with EGFR TKIs compared to when treated with chemotherapy. ${ }^{(8,9,35)}$

136 Development of diverse mechanisms of resistance and selection of resistant clones in 137 response to treatment

138 The common EGFR mutations are located in the tyrosine kinase domain (exon 18-21) of the 
139 EGFR gene, with detection of L858R and deletions in exon 19 the clinical priority as these 140 determine sensitivity to first and second generation TKIs. ${ }^{(36)}$ The T790M mutation in exon 20 141 results in resistance to these therapies. ${ }^{(37)}$ Sensitive assays suggest that tumour clones 142 harbouring the T790M mutation are often detectable prior to initiation of a first generation 143 TKI but can also occur by genetic evolution in T790M mutation negative drug tolerant cells in

144 response to treatment. ${ }^{(38-40)}$ Identification of this resistance mutation is more critical 145 following the development of the third generation EGFR TKIs active against T790M mutation 146 positive NSCLCs. ${ }^{(41,42)}$ But whether these T790M resistant clones pre-exist or evolve in 147 response to treatment may have clinical implications with differing sensitivities to third 148 generation TKIs. ${ }^{(40)}$ The capacity for tumours to evolve in response to first generation TKIs 149 results in an additional diverse array of mechanisms of resistance such as amplification of 150 MET, selection for PIK3CA or BRAF mutations and transformation to a small cell 151 phenotype. ${ }^{(43)}$ Clearly, cancer evolution and selection of resistant subclones is not restricted 152 to first generation TKIs. This is highlighted by recent reports of the emergence of T790M 153 mutation negative disease and the development of novel secondary EGFR resistance 154 mutations (C797S) after treatment of T790M mutation positive patients with third 155 generation TKIs. ${ }^{(44,45)}$

\section{EGFR mutation testing}

158 The nature of EGFR sensitizing mutations, being single nucleotide variants (SNV) or short 159 deletions, lends themselves to molecular analysis of formalin fixed small samples which 160 contain fragmented DNA. ${ }^{(46)}$ There are a variety of methods to detect EGFR mutations 161 including conventional Sanger sequencing, amplification refractory mutations systems 162 (ARMS), restriction fragment length polymorphisms and more recently as part of targeted 163 NGS panels. ${ }^{(47,48)}$ Reporting the limitations of an assay along with the result is critical for 164 clinical interpretation. Bi-directional Sanger sequencing without a mutation enrichment step 165 has a lower limit of detection of $10-25 \%$ of total DNA meaning that the use of samples with 166 low tumour cellularity can result in false negative mutation calls. Consequently the use of 167 methods that can detect mutations in low tumour cellularity samples $(<10 \%)$ is 168 recommended. Polymerase chain reaction (PCR) based ultra sensitive and NGS methods can 169 generate artefact mutations leading to false positive results. However techniques, such as 170 duplex sequencing, are being developed to overcome the inherent error rate in sequencing 171 technologis $^{(49)}$ Formalin fixed samples are particularly prone to DNA damage and display 172 disproportionate levels of $C>T / G>A$ changes in the 1-10\% allele frequency range which can 
173 result in false positive mutation calls. ${ }^{(50)}$ Publication of clinical trials results on response to 174 EGFR TKI in patients with real but less common EGFR mutations can help guide clinical 175 decision-making. ${ }^{(51)}$ Detection of EGFR mutations as part of a WES or WGS analysis allows 176 multiple driver mutations to be queried simultaneously but the performance of 177 bioinformatics tools to call mutations from NGS data varies. Such complexities need to be 178 considered as these technologies are increasingly adopted into mainstream clinical 179 practice. ${ }^{(52-54)}$

\section{EGFR mutations, resistance and tumour heterogeneity}

182 There are very few reports of discordance of EGFR mutation status between primary disease

183 and metastatic sites and these may be due to technical limitations of the assays used. ${ }^{(55)}$ Loss

184 of the EGFR mutation was not a mechanism seen in seminal studies. ${ }^{(43)}$ Studies looking at the 185 extent of intra tumour heterogeneity (ITH) in early lung cancer have shown EGFR to be 186 exclusively a clonal event prevalent throughout the tumour. ${ }^{(56,57)}$ As resistance to EGFR TKI is 187 usually due to acquisition of secondary mutations in EGFR or other driver genes the key 188 challenge at the time of disease progression is to obtain a contemporaneous sample to 189 inform selection of second line therapy. In general the most easily accessible lesion is used 190 but in patients with a poor performance status this may not be a trivial task. Due to tumour 191 heterogeneity it is possible that a single sample may be insufficient to accurately represent 192 all the resistance mechanisms present or the breadth of subclonal driver events present 193 across multiple disease sites following progression on therapy.

195 Current challenges in molecular diagnostics for ALK testing in clinical practice

197 The discovery of an oncogenic anaplastic lymphoma kinase fusion gene (EML4-ALK) in 2007 198 identified another important molecular cohort in NSCLC. ${ }^{(58)}$ Present in $2-7 \%$ of NSCLC ALK 199 fusion genes are restricted to adenocarcinoma subtypes and are more common in younger 200 patients and never-smokers. ${ }^{(59-61)}$ Identification of this cohort is critical given the high 201 response rates $(57-74 \%)$ to ALK inhibition both as a first line therapy and after platinum202 based chemotherapy. ${ }^{(59,62,63)}$ Subsequently other rare fusion genes have been identified 203 involving ROS1, with similar exquisite sensitivity to kinase inhibition, ${ }^{(64)}$ but also RET and 204 NTRK where objective response rates are lower. ${ }^{(65,66)}$

\section{ALK fusion gene detection}


207 Testing for ALK fusion genes brings its own particular set of challenges. ALK is activated by 208 genomic rearrangement, leading to the expression of a chimeric protein containing the 209 effector part of the ALK tyrosine kinase fused to the proximal portion of another protein. In 210 NSCLC cancer this is typically a balanced translocation with the ubiquitously highly expressed 211 EML4 gene, ${ }^{(58)}$ although rarely other partner genes may be involved. ${ }^{(67,68)}$ Expression of the 212 chimeric protein leads to upregulation of mitogenic signalling through the RAS/RAF pathway 213 and interruption of this pathway by ALK inhibitors causes cancer cell death and tumour 214 regression. ${ }^{(62)}$ ALK-mutated tumours often show unusual features on conventional 215 microscopy, such as cribriform growth patterns and 'signet ring' cells with large vacuoles, ${ }^{(69)}$ 216 but this is not sufficiently sensitive or specific to guide treatment.

218 The first widely adopted test for ALK-driven tumours was FISH (fluorescence in situ 219 hybridisation), approved by the FDA (US Food and Drug Administration) in $2011 .{ }^{(70)} \mathrm{FISH}$ is a 220 technically demanding method, requiring specialised equipment and experienced 221 practitioners. Tissue sections or cytology specimens are subjected to a protocol that labels 222 either side of the ALK breakpoint locus with red and green fluorescent DNA probes. In non223 transformed cell nuclei the coloured dots overlap and look yellow, while in translocated cells 224 isolated red and/or green signals are seen. For a reliable FISH assay the tissue must be 225 adequate in quantity and quality. This can be more challenging with small biopsy samples 226 which may contain few cells or which show crushing artefacts that can impair interpretation.

228 In 2015, an immunohistochemistry method was approved by the FDA. This approach is 229 simpler in principle, using an antibody stain to detect abnormal ALK antigen expression. 230 However, currently available antibodies do not give a strong signal and so an additional 231 signal amplification steps needs to be employed. This places the test beyond the capacity of 232 many small labs. Nonetheless, the modified test is cheaper than FISH, easier to interpret, 233 and has the theoretical advantage of additionally detecting ALK expression following rare 234 atypical rearrangements. After much investigation, recent studies suggest 235 immunohistochemistry can be an adequate stand-alone diagnostic, showing extremely high 236 concordance with FISH. ${ }^{(71)}$ UK guidelines do not dictate which test should be applied, and 237 practices vary regionally, though FISH is still often regarded as the 'gold standard' and is 238 considered the definitive test in the US. ${ }^{(48)}$ As our understanding of tumour taxonomy and 239 genotypes advances, it seems inevitable that some form of NGS platform will become the 240 clinical standard for gene fusion detection. ${ }^{(72)}$ These methods have the potential to detect 
241 ALK (and other) rearrangements in either a targeted panel or a WES or WGS approach. ${ }^{(73,74)}$ 242 (72)

\section{ALK fusion genes, resistance and tumour heterogeneity}

245 ALK fusion genes are considered to be clonal events with minimal discordance between

246 primary and metastatic lesions. ${ }^{(75)}$ They were considered to be mutually exclusive with EGFR

247 mutations however recent reports suggests a small minority of tumours can contain both

248 ALK and EGFR positive clones. ${ }^{(76-78)}$ The mechanisms of resistance seen following ALK

249 inhibitor therapy again demonstrate tumour evolution with secondary mutations in ALK, ALK

250 copy number gain, secondary driver mutations in other genes and outgrowth of ALK fusion

251 gene negative clones reported. ${ }^{(79-82)}$ Consequently contemporaneous sampling of

252 progressive disease, by needle biopsy or analysis of cfDNA, may allow real time analysis of

253 tumour evolution and guide therapy.

\section{Integration of multi-gene NGS testing in clinical practice}

256 Routine molecular profiling can be performed at scale on a national level. Large cooperative 257 efforts in France and the USA used combinations of mutation specific PCRs, Sanger 258 sequencing and FISH analysis to assay 6-10 oncogenic drivers in thousands of patients with 259 NSCLC and survival was improved for those treated with gene directed targeted 260 therapies. ${ }^{(83,84)}$ The use of next generation sequencing to simultaneously assay multiple 261 oncogenic drivers is attractive because less DNA is required compared to multiple individual 262 assays, there is a reduction in hands-on laboratory time, and complex FISH analysis for 263 detection of fusion genes may be avoided. A recent NGS approach used an amplicon based 264 approach to assay 14 genes used only 50ng of DNA from FFPE samples. ${ }^{\left({ }^{85}\right)}$ This study 265 provided a comprehensive assessment of the spectrum of mutations, and co-occurrence of 266 mutations, in adenocarcinoma and squamous cell carcinomas with detection turn around 267 times of less than two weeks. These studies and those of The Cancer Genome Atlas highlight 268 the inter-patient molecular heterogeneity of NSCLC (Figure 2). Even within these molecular 269 cohorts intra-tumour heterogeneity could have significant effects on outcome as 270 exemplified by a recent study showing that the clonality of FGFR amplification is an 271 important predictor of response to FGFR inhibition. ${ }^{(86)}$ A deeper understanding of the clonal 272 or subclonal nature of driver events in NSCLC from sufficiently powered studies, is still 273 awaited. Recruitment of patients with rare mutations to molecularly stratified trials is 274 challenging, ${ }^{(87)}$ and some advocate that modifications to existing paradigms in drug 
275 development are required in the era of genomic studies and precision medicine. ${ }^{(88)}$ Multi-

276 gene or WES NGS assays are likely to become standard practice in the years to come and the 277 ultimately automated provision of readable, applicable reports of complex genomic data is 278 another important challenge.

\section{Current challenges in molecular diagnostics for PDL1 testing in clinical practice}

Activation of inhibitory $\mathrm{T}$ cell checkpoint interactions in established tumours has been demonstrated in a number of solid tumours, including NSCLC, and this suppresses the antitumour immune response. ${ }^{(89,90)}$ The aim of immunotherapy using antagonists of these inhibitory T cell checkpoint interactions is to reactivate anti-tumour immunity. PDL1 (B7-H1) is a ligand present on antigen presenting cells (APCs), including tumour cells that interacts with its receptor (PD-1) on T cells and inhibits T cell effector functions. PD-1 and CD8 positive effector T cell population are thought to be the tumour reactive subset responsible for antitumour immunity. ${ }^{(91)}$ There is limited knowledge of the spatial or functional heterogeneity of tumour infiltrating lymphocyte (TIL) populations and the T cell checkpoint ligand-receptor interactions within solid tumours.

Recent randomised trials have shown activity of PD1 and PDL1 targeting antibodies in squamous and non-squamous NSCLC. ${ }^{(92-96)}$ In most instances these agents have shown greater activity in patients whose tumour expresses PDL1 when tested using IHC. However durable responses are seen in patients without PDL1 expression. This is unsurprising given the technical and spatial heterogeneity of PDL1 expression in NSCLC, which hampers its use as a predictive biomarker. ${ }^{(97-99)}$ Studies of the expression of PDL1 on APCs in NSCLC are also contradictory with respect to any correlation with tumour infiltration of the effector CD8 positive T cells. ${ }^{(89,97,98)}$

Regulation of PDL1 expression is complex and controlled by both cell intrinsic and cell extrinsic factors. ${ }^{(100)}$ This means that oncogene driven expression of PDL1 can result in increased expression in the absence of significant underlying immunogenicity. ${ }^{(101)}$ This

305 underlying immunogenicity is thought to be a result of non-synonymous SNVs which 306 generate neoantigens, mutated proteins, recognised by the TIL population. ${ }^{(102,103)}$ The 307 number of neoantigens harboured by a tumour could act as a potential biomarker for 308 immunotherapy although there are technical challenges inherent with such complex 
assessments. Recent data also suggest that neo-antigen intratumour heterogeneity may also

310 be associated with altered checkpoint inhibitor response, which may further complicate the

311 use of such assays in a clinical setting. ${ }^{(104)}$

313 The advent of immunotherapy presents additional challenges for molecular diagnostics in

314 NSCLC. Although IHC for PDL1 can be performed on the small samples often used in lung 315 cancer diagnostics there is the risk of significant sampling bias because of ITH. The dynamic 316 nature of PDL1 gene expression, ${ }^{(105,106)}$ means a contemporaneous sample obtained by 317 repeat biopsy may be the most accurate adding additional burden and expense to current 318 clinical pathways. Characterisation of neo-antigens as a potential biomarker would require 319 sufficient tumour DNA for WES and carries significant expense but given the cost of these 320 therapies would be justified if the assay were sufficiently predictive. However neo-antigen 321 prediction algorithms are still in their infancy and evidence suggests that there are a 322 proportion of patients who derive no clinical benefit from checkpoint inhibitor therapy, yet 323 have tumours with a neo-antigen burden above thresholds associated with sensitivity and 324 conversely patients with low neo-antigen burden who benefit.

Molecular diagnostics in practice: The United Kingdom National Lung Matrix Trial

The Cancer Research UK Stratified Medicine Programme 2 (SMP2) screens samples from advanced NSCLC patients using NGS for known drivers that are considered clinically actionable. The aim of SMP2 is to establish high-throughput and quality genomic screening at a national level in the UK. Based on these results, patients are recruited to The National Lung Matrix Trial (NLMT) (NCT02664935) a phase II umbrella study with both targeted

333 therapy and immunotherapy arms for patients who have progressed on first line therapy. ${ }^{(107)}$

334 In comparison, the Lung-MAP (NCT02154490) and SAFIR02 Lung trial (NCT02117167) are

335 umbrella studies, outside of the UK, for patients with NSCLC where recruitment is preceded 336 by molecular stratification (Table 1 ).

338 SMP2 molecular pathology workflow utilises DNA from excess diagnostic biopsy tissue. 339 Sections are sent from the referring clinical site and extracted by one of three central 340 technology hubs. Samples with sufficient amounts of DNA (>50ng) are then analysed using a 341 custom 28-gene targeted NGS panel. Having successfully screened over 1000 patients, 342 patterns of mutation and prevalence are emerging across the genomic and clinical data. 
343 Preliminary analysis indicates prevalence and distribution of SNVs consistent to published 344 reports, including $31.6 \%$ KRAS (of which $19.7 \%$ show concomitant STK11 mutation) and 345 15.1\% EGFR mutations in patients with adenocarcinoma. Over the past year, SMP2 has led 346 to the recruitment of over 60 patients to the NLMT. A number of detailed audits have 347 identified areas of improvement along the SMP2 pathway; from patient recruitment, to 348 sample preparation and result analysis.

350 Whilst utilising excess DNA from the FFPE diagnostic biopsy has significant advantage for 351 patients and clinical workload (as repeat biopsies are not required), only $70 \%$ of samples 352 sent have sufficient DNA to enter the sequencing pipeline. This is in part due to FFPE blocks 353 being exhausted during the diagnostic process and a general reduction in the size of 354 diagnostic cores over time. Consequently the minimum number of sections has since been 355 increased to ensure enough DNA is obtained up front. Some recruiting centres quantify DNA 356 upfront, which allows a faster feedback loop if insufficient DNA is present. Sites can then 357 obtain additional sample from the diagnostic block or through re-biopsy, if appropriate. 358 However, differences in quantification methodology between local clinical centres and 359 central technology hubs have led to samples being sent with less than the required 50ng, 360 resulting some of these samples failing quality control metrics prior to sequencing. As a 361 result changes in extraction methods and a standardized DNA concentration have been 362 introduced.

364 Unique to NLMT is the need to determine wild type status of some genes for eligibility to 365 certain arms. Patients recruited to the CDK4/6 inhibitor palbociclib arm must have wildtype 366 retinoblastoma 1 protein (RB1) in addition to deficiencies in cell cycle regulation. The 367 determination of wildtype status requires a pre-sequencing assessment of tumour cellularity 368 to determine appropriate sequencing depth. However there can be significant discordance 369 between pathologist assessments of this. ${ }^{(108)}$ Clearer guidance and online training should 370 ensure more concordance for visual assessment, whilst digital solutions may provide a useful 371 alternative. A number of computational methods exist to assess tumour purity and control 372 for both stromal cell admixture and cancer cell ploidy in DNA samples from next generation 373 sequencing data. ${ }^{(109,110)}$

375 Extremes of GC nucleotide content in certain genes (RB1 and FGFR3) can result in an 376 increased number of sequencing failures. Additional probe coverage in the targeted panel 
and correction for GC content in the data processing stage will improve results for these

378 difficult to sequence regions. Following these incremental improvements at each step of the molecular pathology workflow we have shown that the number of successfully sequenced samples that would allow recruitment to the NLMT increased and there has also been an increase in identification of potentially actionable mutations that would permit recruitment to trials other than the NLMT.

\section{Future solutions}

\section{Understanding tumour heterogeneity and cancer evolution}

At present the technical limitation of the small, and potentially low tumour cellularity NSCLC samples, obtained from bronchoscopic and EBUS-TBNA samples means that the main challenge facing clinicians and pathologists is the need for ever greater amounts of information from diminishing amounts of tissue. It is therefore imperative that the quality of diagnostic samples in the advanced NSCLC setting is of the highest order. How best to achieve this represents a challenge for health service providers that has received very little attention thus far. However the spectre of ITH and cancer evolution means that sampling bias and the presence of subclonal driver mutations, causing resistance to therapy, are likely to hinder clinical benefit of targeted therapeutics. ${ }^{(111,112)}$ The UK Lung TRAcking Cancer Evolution through Therapy trial (NCT01888601) is currently characterizing the extent of ITH in early surgically resected NSCLC and with longitudinal follow-up aims to determine the origins of tumour subclones contributing to relapse. ${ }^{(17)}$ There is evidence from other tumour types of parallel evolution, acquisition of mutations in the same gene or signalling pathway

400 in distinct subclones, that may highlight an 'evolutionary bottle neck' that could be an

401 Achilles heel for subsequent cancer therapy. ${ }^{(113-115)}$ Clonal analyses of a drug target and 402 putative resistance events, whether they are present in all tumor cells or only a proportion, 403 may affect the response rate and progression free survival times on targeted therapy and 404 this is being addressed in clinical trials including the DARWIN studies (NCT02314481, 405 NCT02183883). Ultimately it may be that only through 'warm' autopsy studies, where 406 subclonal phylogenetic structures can be determined through sampling multiple sites of 407 disease, that effective strategies to forestall cancer evolution can be elucidated. ${ }^{(116)}$

\section{Circulating biomarkers}

410 The use of minimally invasive methods to detect mutations in circulating cell-free DNA 
411 (cfDNA) or 'liquid biopsies' offers the potential to obtain a mutation call in a patient where

412 an invasive biopsy may not be feasible. As tumour DNA from all sites of disease has the 413 potential to enter the blood stream it may also be a better reflection of tumour

414 heterogeneity than a single biopsy. ${ }^{(117,118)}$ The use of cfDNA to detect resistance mechanisms

415 in patients treated with EGFR TKIs, often prior to radiographic progression, has been

416 demonstrated. ${ }^{(45,119,120)}$ This has resulted in the development and approval of a commercially

417 available assay of cfDNA in plasma that can detect a spectrum of EGFR mutations in

418 including the T790M mutation amenable to targeting with third generation TKIs.

420 Circulating tumour cells (CTCS) are tumour cells that can be isolated from the peripheral

421 blood and are a complementary circulating biomarker to cfDNA. CTCs are a versatile tool,

422 cell enumeration can be prognostic, immunohistochemistry permits further characterization,

423 single cell DNA or RNA sequencing is possible and tumour xenografts can be generated to

424 assess drug response. ${ }^{(121-125)}$ However at present the complexity of separation from other

425 cells in the peripheral circulation and the need to process samples promptly for functional or

426 genomic studies results in greater expense in comparison to cfDNA analysis. Circulating

427 biomarkers will make a significant impact on cancer management in the near future and

428 readers are directed to more extensive reviews focusing on CTCs, cfDNA and other

429 circulating nucleotides. ${ }^{(121,126-129)}$

430

\section{Conclusion}

432 The challenges for molecular diagnostics in NSCLC are largely paralleled across other tumour

433 types. Resolving these issues will require technology improvements in addition to a greater

434 understanding of tumour biology. The logistical challenges of implementing the next

435 generation of molecular diagnostics into clinical practice are equally as challenging. Clinical

436 governance, information technology infrastructure, data storage, pathways in sample

437 processing and training and professional developments in histopathology, respiratory

438 medicine and oncology will need investment. With these great challenges comes significant

439 opportunity to improve the success rate and efficiency of drug development in NSCLC and

$440 \quad$ ultimately patient outcomes.

442 Conflicts of interest: None 
Figure 1: Summary of the key technical, logistical and biological challenges for molecular testing in NSCLC.

Figure 2: Pie charts showing the approximate distribution of clinically relevant driver mutations identified to date in individuals with NSCLC. The genomic variants shown are potentially clinically actionable variants. ${ }^{(130)}$ The proportions presented are based on estimates from the referenced studies and data sources, including the Stratified Medicine Programme 2 (unpublished data). ${ }^{(2,3,85,131)}$ These studies examine SNVs, copy number variants and gene fusion products using different sequencing technologies and sequencing depth resulting in inter-study variation and therefore the data is presented in aggregate form and represents an approximation. CCGA (Cell cycle genomic aberration); loss of Cyclin-Dependent Kinase Inhibitor $2 A$ or amplification of Cyclin-Dependent Kinase 4 or Cyclin D1 in the presence of wildtype RB1. ${ }^{(107)}$ EGFR, Epidermal growth factor receptor; LKB1, Liver Kinase B1; ALK, anaplastic lymphoma kinase; MET, MET Proto-Oncogene, Receptor Tyrosine Kinase; FGFR, fibroblastic growth factor receptor; NRAS, neuroblastoma RAS viral (v-ras) oncogene homolog; DDR2 Discoidin Domain Receptor Tyrosine Kinase 2; AKT1, v-akt murine thymoma viral oncogene homolog 1; PTEN, Phosphatase And Tensin Homolog; PIK3CA, phosphoinositide-3-kinase, catalytic, a polypeptide; BRAF, v-raf murine sarcoma viral oncogene homolog B1; ERBB2, human epidermal growth factor receptor 2; KRAS, v-Ki-ras2 Kirsten rat sarcoma viral oncogene homolog; TP53, Tumor Protein P53.

Table 1: Comparison of molecularly stratified umbrella studies in NSCLC. PFS = progression free survival, $\mathrm{ORR}=$ objective response rate, $\mathrm{R}=$ randomised, $\mathrm{NR}=$ non-randomised, $\mathrm{SCC}=$ squamous cell carcinoma, CCGA = cell cycle genomic aberration . 


\section{REFERENCES}

1. Lung Cancer Key Statistics. United Kingdom: Cancer Research UK, 2015.

2. Cancer Genome Atlas Research N. Comprehensive genomic characterization of squamous cell lung cancers. Nature. 2012;489(7417):519-25.

3. Cancer Genome Atlas Research N. Comprehensive molecular profiling of lung adenocarcinoma. Nature. 2014;511(7511):543-50.

4. Swanton C, Govindan R. Clinical Implications of Genomic Discoveries in Lung Cancer. The New England journal of medicine. 2016;374(19):1864-73.

5. Schiller JH, Harrington D, Belani CP, et al. Comparison of four chemotherapy regimens for advanced non-small-cell lung cancer. The New England journal of medicine. 2002;346(2):92-8.

6. Scagliotti GV, De Marinis F, Rinaldi M, et al. Phase III randomized trial comparing three platinumbased doublets in advanced non-small-cell lung cancer. Journal of clinical oncology : official journal of the American Society of Clinical Oncology. 2002;20(21):4285-91.

7. Kelly K, Crowley J, Bunn PA, Jr., et al. Randomized phase III trial of paclitaxel plus carboplatin versus vinorelbine plus cisplatin in the treatment of patients with advanced non--small-cell lung cancer: a Southwest Oncology Group trial. Journal of clinical oncology : official journal of the American Society of Clinical Oncology. 2001;19(13):3210-8.

8. Mok TS, Wu YL, Thongprasert S, et al. Gefitinib or carboplatin-paclitaxel in pulmonary adenocarcinoma. The New England journal of medicine. 2009;361(10):947-57.

9. Rosell R, Carcereny E, Gervais R, et al. Erlotinib versus standard chemotherapy as first-line treatment for European patients with advanced EGFR mutation-positive non-small-cell lung cancer (EURTAC): a multicentre, open-label, randomised phase 3 trial. The lancet oncology. 2012;13(3):239-46.

10. Ciuleanu T, Brodowicz T, Zielinski C, et al. Maintenance pemetrexed plus best supportive care versus placebo plus best supportive care for non-small-cell lung cancer: a randomised, double-blind, phase 3 study. Lancet. 2009;374(9699):1432-40.

11. Scagliotti GV, Parikh P, von Pawel J, et al. Phase III study comparing cisplatin plus gemcitabine with cisplatin plus pemetrexed in chemotherapy-naive patients with advanced-stage non-small-cell lung cancer. Journal of clinical oncology : official journal of the American Society of Clinical Oncology. 2008;26(21):3543-51.

12. Reck M, Popat S, Reinmuth N, et al. Metastatic non-small-cell lung cancer (NSCLC): ESMO Clinical Practice Guidelines for diagnosis, treatment and follow-up. Annals of oncology : official journal of the European Society for Medical Oncology / ESMO. 2014;25 Suppl 3:iii27-39.

13. Masters GA, Temin S, Azzoli CG, et al. Systemic Therapy for Stage IV Non-Small-Cell Lung Cancer: American Society of Clinical Oncology Clinical Practice Guideline Update. Journal of clinical oncology : official journal of the American Society of Clinical Oncology. 2015;33(30):3488-515. 
14. Kerr KM, Bubendorf L, Edelman MJ, et al. Second ESMO consensus conference on lung cancer: pathology and molecular biomarkers for non-small-cell lung cancer. Annals of oncology : official journal of the European Society for Medical Oncology / ESMO. 2014;25(9):1681-90.

15. Terry J, Leung S, Laskin J, Leslie KO, Gown AM, Ionescu DN. Optimal immunohistochemical markers for distinguishing lung adenocarcinomas from squamous cell carcinomas in small tumor samples. Am J Surg Pathol. 2010;34(12):1805-11.

16. Zhang C, Schmidt LA, Hatanaka K, Thomas D, Lagstein A, Myers JL. Evaluation of napsin A, TTF-1, p63, p40, and CK5/6 immunohistochemical stains in pulmonary neuroendocrine tumors. Am J Clin Pathol. 2014;142(3):320-4.

17. Jamal-Hanjani M, Hackshaw A, Ngai Y, et al. Tracking genomic cancer evolution for precision medicine: the lung TRACERx study. PLoS biology. 2014;12(7):e1001906.

18. Audit NLC. NLCA Annual Report. London: Royal College of Physicians, 2015.

19. Rivera MP, Mehta AC, Wahidi MM. Establishing the diagnosis of lung cancer: Diagnosis and management of lung cancer, 3rd ed: American College of Chest Physicians evidence-based clinical practice guidelines. Chest. 2013;143(5 Suppl):e142S-65S.

20. Kinsey CM, Arenberg DA. Endobronchial ultrasound-guided transbronchial needle aspiration for non-small cell lung cancer staging. Am J Respir Crit Care Med. 2014;189(6):640-9.

21. Navani N, Brown JM, Nankivell M, et al. Suitability of endobronchial ultrasound-guided transbronchial needle aspiration specimens for subtyping and genotyping of non-small cell lung cancer: a multicenter study of 774 patients. Am J Respir Crit Care Med. 2012;185(12):1316-22.

22. Santis G, Angell R, Nickless G, et al. Screening for EGFR and KRAS mutations in endobronchial ultrasound derived transbronchial needle aspirates in non-small cell lung cancer using COLD-PCR. PLoS One. 2011;6(9):e25191.

23. Nakajima T, Yasufuku K, Nakagawara A, Kimura H, Yoshino I. Multigene mutation analysis of metastatic lymph nodes in non-small cell lung cancer diagnosed by endobronchial ultrasound-guided transbronchial needle aspiration. Chest. 2011;140(5):1319-24.

24. van Eijk R, Licht J, Schrumpf M, et al. Rapid KRAS, EGFR, BRAF and PIK3CA mutation analysis of fine needle aspirates from non-small-cell lung cancer using allele-specific qPCR. PLoS One. 2011;6(3):e17791.

25. Kanagal-Shamanna R, Portier BP, Singh RR, et al. Next-generation sequencing-based multi-gene mutation profiling of solid tumors using fine needle aspiration samples: promises and challenges for routine clinical diagnostics. Mod Pathol. 2014;27(2):314-27.

26. Qiu T, Guo H, Zhao H, Wang L, Zhang Z. Next-generation sequencing for molecular diagnosis of lung adenocarcinoma specimens obtained by fine needle aspiration cytology. Scientific reports. 2015;5:11317.

27. Kris MG, Natale RB, Herbst RS, et al. Efficacy of gefitinib, an inhibitor of the epidermal growth factor receptor tyrosine kinase, in symptomatic patients with non-small cell lung cancer: a randomized trial. JAMA. 2003;290(16):2149-58. 
28. Fukuoka M, Yano S, Giaccone G, et al. Multi-institutional randomized phase II trial of gefitinib for previously treated patients with advanced non-small-cell lung cancer (The IDEAL 1 Trial) [corrected]. Journal of clinical oncology : official journal of the American Society of Clinical Oncology.

2003;21(12):2237-46.

29. Thatcher N, Chang A, Parikh P, et al. Gefitinib plus best supportive care in previously treated patients with refractory advanced non-small-cell lung cancer: results from a randomised, placebocontrolled, multicentre study (Iressa Survival Evaluation in Lung Cancer). Lancet. 2005;366(9496):152737.

30. Giaccone G, Herbst RS, Manegold C, et al. Gefitinib in combination with gemcitabine and cisplatin in advanced non-small-cell lung cancer: a phase III trial--INTACT 1. Journal of clinical oncology : official journal of the American Society of Clinical Oncology. 2004;22(5):777-84.

31. Lynch TJ, Bell DW, Sordella R, et al. Activating mutations in the epidermal growth factor receptor underlying responsiveness of non-small-cell lung cancer to gefitinib. The New England journal of medicine. 2004;350(21):2129-39.

32. Paez JG, Janne PA, Lee JC, et al. EGFR mutations in lung cancer: correlation with clinical response to gefitinib therapy. Science (New York, NY. 2004;304(5676):1497-500.

33. Pao W, Miller V, Zakowski M, et al. EGF receptor gene mutations are common in lung cancers from "never smokers" and are associated with sensitivity of tumors to gefitinib and erlotinib. Proceedings of the National Academy of Sciences of the United States of America. 2004;101(36):1330611.

34. Bell DW, Lynch TJ, Haserlat SM, et al. Epidermal growth factor receptor mutations and gene amplification in non-small-cell lung cancer: molecular analysis of the IDEAL/INTACT gefitinib trials. Journal of clinical oncology : official journal of the American Society of Clinical Oncology. 2005;23(31):8081-92.

35. Yang JC, Wu YL, Schuler M, et al. Afatinib versus cisplatin-based chemotherapy for EGFR mutation-positive lung adenocarcinoma (LUX-Lung 3 and LUX-Lung 6): analysis of overall survival data from two randomised, phase 3 trials. The lancet oncology. 2015;16(2):141-51.

36. Sharma SV, Bell DW, Settleman J, Haber DA. Epidermal growth factor receptor mutations in lung cancer. Nature reviews Cancer. 2007;7(3):169-81.

37. Pao W, Miller VA, Politi KA, et al. Acquired resistance of lung adenocarcinomas to gefitinib or erlotinib is associated with a second mutation in the EGFR kinase domain. PLoS Med. 2005;2(3):e73.

38. Inukai M, Toyooka S, Ito S, et al. Presence of epidermal growth factor receptor gene T790M mutation as a minor clone in non-small cell lung cancer. Cancer Res. 2006;66(16):7854-8.

39. Su KY, Chen HY, Li KC, et al. Pretreatment epidermal growth factor receptor (EGFR) T790M mutation predicts shorter EGFR tyrosine kinase inhibitor response duration in patients with non-smallcell lung cancer. Journal of clinical oncology : official journal of the American Society of Clinical Oncology. 2012;30(4):433-40.

40. Hata AN, Niederst MJ, Archibald HL, et al. Tumor cells can follow distinct evolutionary paths to become resistant to epidermal growth factor receptor inhibition. Nature medicine. 2016;22(3):262-9. 
41. Janne PA, Yang JC, Kim DW, et al. AZD9291 in EGFR inhibitor-resistant non-small-cell lung cancer. The New England journal of medicine. 2015;372(18):1689-99.

42. Sequist LV, Soria JC, Goldman JW, et al. Rociletinib in EGFR-mutated non-small-cell lung cancer. The New England journal of medicine. 2015;372(18):1700-9.

43. Sequist LV, Waltman BA, Dias-Santagata D, et al. Genotypic and histological evolution of lung cancers acquiring resistance to EGFR inhibitors. Sci Transl Med. 2011;3(75):75ra26.

44. Piotrowska Z, Niederst MJ, Karlovich CA, et al. Heterogeneity Underlies the Emergence of EGFRT790 Wild-Type Clones Following Treatment of T790M-Positive Cancers with a Third-Generation EGFR Inhibitor. Cancer discovery. 2015;5(7):713-22.

45. Thress KS, Paweletz CP, Felip E, et al. Acquired EGFR C797S mutation mediates resistance to AZD9291 in non-small cell lung cancer harboring EGFR T790M. Nature medicine. 2015;21(6):560-2.

46. Williams C, Ponten F, Moberg C, et al. A high frequency of sequence alterations is due to formalin fixation of archival specimens. The American journal of pathology. 1999;155(5):1467-71.

47. Pirker R, Herth FJ, Kerr KM, et al. Consensus for EGFR mutation testing in non-small cell lung cancer: results from a European workshop. Journal of thoracic oncology : official publication of the International Association for the Study of Lung Cancer. 2010;5(10):1706-13.

48. Lindeman NI, Cagle PT, Beasley MB, et al. Molecular testing guideline for selection of lung cancer patients for EGFR and ALK tyrosine kinase inhibitors: guideline from the College of American Pathologists, International Association for the Study of Lung Cancer, and Association for Molecular Pathology. Journal of thoracic oncology : official publication of the International Association for the Study of Lung Cancer. 2013;8(7):823-59.

49. Schmitt MW, Kennedy SR, Salk JJ, Fox EJ, Hiatt JB, Loeb LA. Detection of ultra-rare mutations by next-generation sequencing. Proceedings of the National Academy of Sciences of the United States of America. 2012;109(36):14508-13.

50. Wong SQ, Li J, Tan AY, et al. Sequence artefacts in a prospective series of formalin-fixed tumours tested for mutations in hotspot regions by massively parallel sequencing. BMC medical genomics. 2014;7:23.

51. Yang JC, Sequist LV, Geater SL, et al. Clinical activity of afatinib in patients with advanced nonsmall-cell lung cancer harbouring uncommon EGFR mutations: a combined post-hoc analysis of LUXLung 2, LUX-Lung 3, and LUX-Lung 6. The lancet oncology. 2015;16(7):830-8.

52. Lai Z, Markovets A, Ahdesmaki M, et al. VarDict: a novel and versatile variant caller for nextgeneration sequencing in cancer research. Nucleic Acids Res. 2016.

53. O'Rawe J, Jiang T, Sun G, et al. Low concordance of multiple variant-calling pipelines: practical implications for exome and genome sequencing. Genome medicine. 2013;5(3):28.

54. Rehm HL, Bale SJ, Bayrak-Toydemir P, et al. ACMG clinical laboratory standards for nextgeneration sequencing. Genet Med. 2013;15(9):733-47.

55. Park S, Holmes-Tisch AJ, Cho EY, et al. Discordance of molecular biomarkers associated with epidermal growth factor receptor pathway between primary tumors and lymph node metastasis in non- 
small cell lung cancer. Journal of thoracic oncology : official publication of the International Association for the Study of Lung Cancer. 2009;4(7):809-15.

56. Zhang J, Fujimoto J, Zhang J, et al. Intratumor heterogeneity in localized lung adenocarcinomas delineated by multiregion sequencing. Science (New York, NY. 2014;346(6206):256-9.

57. de Bruin EC, McGranahan N, Mitter R, et al. Spatial and temporal diversity in genomic instability processes defines lung cancer evolution. Science (New York, NY. 2014;346(6206):251-6.

58. Soda M, Choi YL, Enomoto M, et al. Identification of the transforming EML4-ALK fusion gene in non-small-cell lung cancer. Nature. 2007;448(7153):561-6.

59. Kwak EL, Bang YJ, Camidge DR, et al. Anaplastic lymphoma kinase inhibition in non-small-cell lung cancer. The New England journal of medicine. 2010;363(18):1693-703.

60. Koivunen JP, Mermel C, Zejnullahu K, et al. EML4-ALK fusion gene and efficacy of an ALK kinase inhibitor in lung cancer. Clin Cancer Res. 2008;14(13):4275-83.

61. Zhao W, Choi YL, Song JY, et al. ALK, ROS1 and RET rearrangements in lung squamous cell carcinoma are very rare. Lung Cancer. 2016;94:22-7.

62. Shaw AT, Kim DW, Nakagawa K, et al. Crizotinib versus chemotherapy in advanced ALK-positive lung cancer. The New England journal of medicine. 2013;368(25):2385-94.

63. Solomon BJ, Mok T, Kim DW, et al. First-line crizotinib versus chemotherapy in ALK-positive lung cancer. The New England journal of medicine. 2014;371(23):2167-77.

64. Shaw AT, Ou SH, Bang YJ, et al. Crizotinib in ROS1-rearranged non-small-cell lung cancer. The New England journal of medicine. 2014;371(21):1963-71.

65. Takeuchi K, Soda M, Togashi Y, et al. RET, ROS1 and ALK fusions in lung cancer. Nature medicine. 2012;18(3):378-81.

66. Vaishnavi A, Capelletti M, Le AT, et al. Oncogenic and drug-sensitive NTRK1 rearrangements in lung cancer. Nature medicine. 2013;19(11):1469-72.

67. Iyevleva AG, Raskin GA, Tiurin VI, et al. Novel ALK fusion partners in lung cancer. Cancer Lett. 2015;362(1):116-21.

68. Takeuchi K, Choi YL, Togashi Y, et al. KIF5B-ALK, a novel fusion oncokinase identified by an immunohistochemistry-based diagnostic system for ALK-positive lung cancer. Clin Cancer Res. 2009;15(9):3143-9.

69. Yoshida A, Tsuta K, Nakamura $\mathrm{H}$, et al. Comprehensive histologic analysis of ALK-rearranged lung carcinomas. Am J Surg Pathol. 2011;35(8):1226-34.

70. IASLC atlas of alk testing in lung cancer: International Association for the Study of Lung Cancer Press; 2013.

71. Takeuchi K, Togashi Y, Kamihara Y, et al. Prospective and clinical validation of ALK immunohistochemistry: results from the phase I/II study of alectinib for ALK-positive lung cancer (AF001JP study). Ann Oncol. 2016;27(1):185-92. 
72. Davare MA, Tognon CE. Detecting and targetting oncogenic fusion proteins in the genomic era. Biol Cell. 2015;107(5):111-29.

73. Drilon A, Wang L, Arcila ME, et al. Broad, Hybrid Capture-Based Next-Generation Sequencing Identifies Actionable Genomic Alterations in Lung Adenocarcinomas Otherwise Negative for Such Alterations by Other Genomic Testing Approaches. Clinical cancer research : an official journal of the American Association for Cancer Research. 2015;21(16):3631-9.

74. Jang JS, Wang X, Vedell PT, et al. Custom Gene Capture and Next Generation Sequencing to Resolve Discordant ALK Status by FISH and IHC in Lung Adenocarcinoma. Journal of thoracic oncology : official publication of the International Association for the Study of Lung Cancer. 2016.

75. Hou L WC. Comparative study of ALK rearrangement between primary tumor and paired lymphatic metastasis in NSCLC patients. ASCO 20152015.

76. Cai W, Lin D, Wu C, et al. Intratumoral Heterogeneity of ALK-Rearranged and ALK/EGFR Coaltered Lung Adenocarcinoma. Journal of clinical oncology : official journal of the American Society of Clinical Oncology. 2015;33(32):3701-9.

77. Birkbak NJ, Hiley CT, Swanton C. Evolutionary Precision Medicine: A Role for Repeat Epidermal Growth Factor Receptor Analysis in ALK-Rearranged Lung Adenocarcinoma? Journal of clinical oncology : official journal of the American Society of Clinical Oncology. 2015;33(32):3681-3.

78. Sasaki T, Koivunen J, Ogino A, et al. A novel ALK secondary mutation and EGFR signaling cause resistance to ALK kinase inhibitors. Cancer Res. 2011;71(18):6051-60.

79. Choi YL, Soda M, Yamashita Y, et al. EML4-ALK mutations in lung cancer that confer resistance to ALK inhibitors. The New England journal of medicine. 2010;363(18):1734-9.

80. Doebele RC, Pilling AB, Aisner DL, et al. Mechanisms of resistance to crizotinib in patients with ALK gene rearranged non-small cell lung cancer. Clinical cancer research : an official journal of the American Association for Cancer Research. 2012;18(5):1472-82.

81. Katayama R, Shaw AT, Khan TM, et al. Mechanisms of acquired crizotinib resistance in ALKrearranged lung Cancers. Sci TransI Med. 2012;4(120):120ra17.

82. Shaw AT, Friboulet L, Leshchiner I, et al. Resensitization to Crizotinib by the Lorlatinib ALK Resistance Mutation L1198F. The New England journal of medicine. 2016;374(1):54-61.

83. Barlesi F, Mazieres J, Merlio JP, et al. Routine molecular profiling of patients with advanced nonsmall-cell lung cancer: results of a 1-year nationwide programme of the French Cooperative Thoracic Intergroup (IFCT). Lancet. 2016;387(10026):1415-26.

84. Kris MG, Johnson BE, Berry LD, et al. Using multiplexed assays of oncogenic drivers in lung cancers to select targeted drugs. JAMA. 2014;311(19):1998-2006.

85. Konig K, Peifer M, Fassunke J, et al. Implementation of Amplicon Parallel Sequencing Leads to Improvement of Diagnosis and Therapy of Lung Cancer Patients. Journal of thoracic oncology : official publication of the International Association for the Study of Lung Cancer. 2015;10(7):1049-57.

86. Pearson A, Smyth E, Babina IS, et al. High-Level Clonal FGFR Amplification and Response to FGFR Inhibition in a Translational Clinical Trial. Cancer discovery. 2016. 
87. Lopez-Chavez A, Thomas A, Rajan A, et al. Molecular profiling and targeted therapy for advanced thoracic malignancies: a biomarker-derived, multiarm, multihistology phase II basket trial. Journal of clinical oncology : official journal of the American Society of Clinical Oncology. 2015;33(9):1000-7.

88. Biankin AV, Piantadosi S, Hollingsworth SJ. Patient-centric trials for therapeutic development in precision oncology. Nature. 2015;526(7573):361-70.

89. Konishi J, Yamazaki K, Azuma M, Kinoshita I, Dosaka-Akita H, Nishimura M. B7-H1 expression on non-small cell lung cancer cells and its relationship with tumor-infiltrating lymphocytes and their PD-1 expression. Clinical cancer research : an official journal of the American Association for Cancer Research. 2004;10(15):5094-100.

90. Taube JM, Anders RA, Young GD, et al. Colocalization of inflammatory response with B7-h1 expression in human melanocytic lesions supports an adaptive resistance mechanism of immune escape. Sci Transl Med. 2012;4(127):127ra37.

91. Gros A, Robbins PF, Yao X, et al. PD-1 identifies the patient-specific CD8(+) tumor-reactive repertoire infiltrating human tumors. The Journal of clinical investigation. 2014;124(5):2246-59.

92. Garon EB, Rizvi NA, Hui R, et al. Pembrolizumab for the treatment of non-small-cell lung cancer. The New England journal of medicine. 2015;372(21):2018-28.

93. Herbst RS, Baas P, Kim DW, et al. Pembrolizumab versus docetaxel for previously treated, PD-L1positive, advanced non-small-cell lung cancer (KEYNOTE-010): a randomised controlled trial. Lancet. 2016;387(10027):1540-50.

94. Borghaei H, Paz-Ares L, Horn L, et al. Nivolumab versus Docetaxel in Advanced Nonsquamous Non-Small-Cell Lung Cancer. The New England journal of medicine. 2015;373(17):1627-39.

95. Brahmer J, Reckamp KL, Baas P, et al. Nivolumab versus Docetaxel in Advanced Squamous-Cell Non-Small-Cell Lung Cancer. The New England journal of medicine. 2015;373(2):123-35.

96. Fehrenbacher L, Spira A, Ballinger $M$, et al. Atezolizumab versus docetaxel for patients with previously treated non-small-cell lung cancer (POPLAR): a multicentre, open-label, phase 2 randomised controlled trial. Lancet. 2016.

97. Taube JM, Klein A, Brahmer JR, et al. Association of PD-1, PD-1 Ligands, and Other Features of the Tumor Immune Microenvironment with Response to Anti-PD-1 Therapy. Clinical cancer research : an official journal of the American Association for Cancer Research. 2014.

98. Velcheti V, Schalper KA, Carvajal DE, et al. Programmed death ligand-1 expression in non-small cell lung cancer. Laboratory investigation; a journal of technical methods and pathology. 2014;94(1):107-16.

99. McLaughlin J, Han G, Schalper KA, et al. Quantitative Assessment of the Heterogeneity of PD-L1 Expression in Non-Small-Cell Lung Cancer. JAMA oncology. 2016;2(1):46-54.

100. Pardoll DM. The blockade of immune checkpoints in cancer immunotherapy. Nature reviews Cancer. 2012;12(4):252-64.

101. Akbay EA, Koyama S, Carretero J, et al. Activation of the PD-1 pathway contributes to immune escape in EGFR-driven lung tumors. Cancer discovery. 2013;3(12):1355-63. 
102. Rizvi NA, Hellmann MD, Snyder A, et al. Cancer immunology. Mutational landscape determines sensitivity to PD-1 blockade in non-small cell lung cancer. Science (New York, NY. 2015;348(6230):124-8.

103. Brown SD, Warren RL, Gibb EA, et al. Neo-antigens predicted by tumor genome meta-analysis correlate with increased patient survival. Genome research. 2014;24(5):743-50.

104. McGranahan N, Furness AJ, Rosenthal R, et al. Clonal neoantigens elicit T cell immunoreactivity and sensitivity to immune checkpoint blockade. Science (New York, NY. 2016;351(6280):1463-9.

105. Patel SP, Kurzrock R. PD-L1 Expression as a Predictive Biomarker in Cancer Immunotherapy. Mol Cancer Ther. 2015;14(4):847-56.

106. Herbst RS, Soria JC, Kowanetz M, et al. Predictive correlates of response to the anti-PD-L1 antibody MPDL3280A in cancer patients. Nature. 2014;515(7528):563-7.

107. Middleton G, Crack LR, Popat S, et al. The National Lung Matrix Trial: translating the biology of stratification in advanced non-small-cell lung cancer. Annals of oncology : official journal of the European Society for Medical Oncology / ESMO. 2015;26(12):2464-9.

108. Shaw EC, Hanby AM, Wheeler K, et al. Observer agreement comparing the use of virtual slides with glass slides in the pathology review component of the POSH breast cancer cohort study. J Clin Pathol. 2012;65(5):403-8.

109. Favero F, Joshi T, Marquard AM, et al. Sequenza: allele-specific copy number and mutation profiles from tumor sequencing data. Annals of oncology : official journal of the European Society for Medical Oncology / ESMO. 2015;26(1):64-70.

110. Van Loo P, Nordgard SH, Lingjaerde OC, et al. Allele-specific copy number analysis of tumors. Proceedings of the National Academy of Sciences of the United States of America. 2010;107(39):169105.

111. Yates LR, Campbell PJ. Evolution of the cancer genome. Nat Rev Genet. 2012;13(11):795-806.

112. Hiley C, de Bruin E, McGranahan N, Swanton C. Deciphering intratumor heterogeneity and temporal acquisition of driver events to refine precision medicine. Genome biology. 2014;15(8):453.

113. Melchor L, Brioli A, Wardell CP, et al. Single-cell genetic analysis reveals the composition of initiating clones and phylogenetic patterns of branching and parallel evolution in myeloma. Leukemia. 2014.

114. Fisher R, Horswell S, Rowan A, et al. Development of synchronous VHL syndrome tumors reveals contingencies and constraints to tumor evolution. Genome biology. 2014;15(8):433.

115. Juric D, Castel P, Griffith M, et al. Convergent loss of PTEN leads to clinical resistance to a PI(3)Kalpha inhibitor. Nature. 2015;518(7538):240-4.

116. Gundem G, Van Loo P, Kremeyer B, et al. The evolutionary history of lethal metastatic prostate cancer. Nature. 2015;520(7547):353-7.

117. Jamal-Hanjani M, Wilson GA, Horswell S, et al. Detection of ubiquitous and heterogeneous mutations in cell-free DNA from patients with early-stage non-small-cell lung cancer. Annals of oncology : official journal of the European Society for Medical Oncology / ESMO. 2016;27(5):862-7. 
118. Murtaza M, Dawson SJ, Tsui DW, et al. Non-invasive analysis of acquired resistance to cancer therapy by sequencing of plasma DNA. Nature. 2013;497(7447):108-12.

119. Oxnard GR, Paweletz CP, Kuang $\mathrm{Y}$, et al. Noninvasive detection of response and resistance in EGFR-mutant lung cancer using quantitative next-generation genotyping of cell-free plasma DNA. Clinical cancer research : an official journal of the American Association for Cancer Research. 2014;20(6):1698-705.

120. Thress KS, Brant R, Carr TH, et al. EGFR mutation detection in ctDNA from NSCLC patient plasma: A cross-platform comparison of leading technologies to support the clinical development of AZD9291. Lung Cancer. 2015;90(3):509-15.

121. Hou JM, Krebs M, Ward T, et al. Circulating tumor cells as a window on metastasis biology in lung cancer. The American journal of pathology. 2011;178(3):989-96.

122. Krebs MG, Sloane R, Priest L, et al. Evaluation and prognostic significance of circulating tumor cells in patients with non-small-cell lung cancer. Journal of clinical oncology : official journal of the American Society of Clinical Oncology. 2011;29(12):1556-63.

123. Maheswaran S, Sequist LV, Nagrath S, et al. Detection of mutations in EGFR in circulating lungcancer cells. The New England journal of medicine. 2008;359(4):366-77.

124. Lohr JG, Adalsteinsson VA, Cibulskis K, et al. Whole-exome sequencing of circulating tumor cells provides a window into metastatic prostate cancer. Nature biotechnology. 2014;32(5):479-84.

125. Hodgkinson CL, Morrow CJ, Li Y, et al. Tumorigenicity and genetic profiling of circulating tumor cells in small-cell lung cancer. Nature medicine. 2014;20(8):897-903.

126. Diaz LA, Jr., Bardelli A. Liquid biopsies: genotyping circulating tumor DNA. Journal of clinical oncology : official journal of the American Society of Clinical Oncology. 2014;32(6):579-86.

127. Alix-Panabieres C, Pantel K. Challenges in circulating tumour cell research. Nature reviews Cancer. 2014;14(9):623-31.

128. Alix-Panabieres C, Pantel K. Clinical Applications of Circulating Tumor Cells and Circulating Tumor DNA as Liquid Biopsy. Cancer discovery. 2016;6(5):479-91.

129. Schwarzenbach H, Hoon DS, Pantel K. Cell-free nucleic acids as biomarkers in cancer patients. Nature reviews Cancer. 2011;11(6):426-37.

130. Dienstmann R, Jang IS, Bot B, Friend S, Guinney J. Database of genomic biomarkers for cancer drugs and clinical targetability in solid tumors. Cancer discovery. 2015;5(2):118-23.

131. Cerami E, Gao J, Dogrusoz U, et al. The cBio cancer genomics portal: an open platform for exploring multidimensional cancer genomics data. Cancer discovery. 2012;2(5):401-4. 


\section{Technical}

- Novel biopsy techniques (eg EBUS) generating smaller samples with diminished tumour cellularity

- Multiple tests with the potential for discordant results (eg IHC vs FISH for ALK mutation)

- Technology-specific failures due to differences in sensitivity/known artefacts (eg sequencing through repeats/high GC areas)

- Quality assurance of genomic medicine despite across multiple platforms and data analysis algorithms

\section{Logistical}

- Turnaround time of assays in a clinically relevant timeframe

- Desirability of centralised vs distributed/local testing approaches

- Education and training of laboratory and clinical staff $n$ new technologies

- Distillation of high volume data into useful standardised reports usable by clinicicans

- Computational and data storage capacity for NGS within a healthcare system

\section{Tumour Biology}

- Diversity of molecular subgroups within NSCLC

- inter-patient heterogeneity

- Intra-tumour heterogeneity

- sampling bias

- differential responses

- Cancer evolution and resistance in response to treatments

- need for longitudinal sampling

- Evolving treatment paradigms

- immuno-oncolog \& new biomarkers (eg PDL-1, neoantigen load)

- Increasing complexity of detectable genomic changes in cancer

- eg epigenetic changes \& non-coding variants 


\section{Adenocarcinoma}

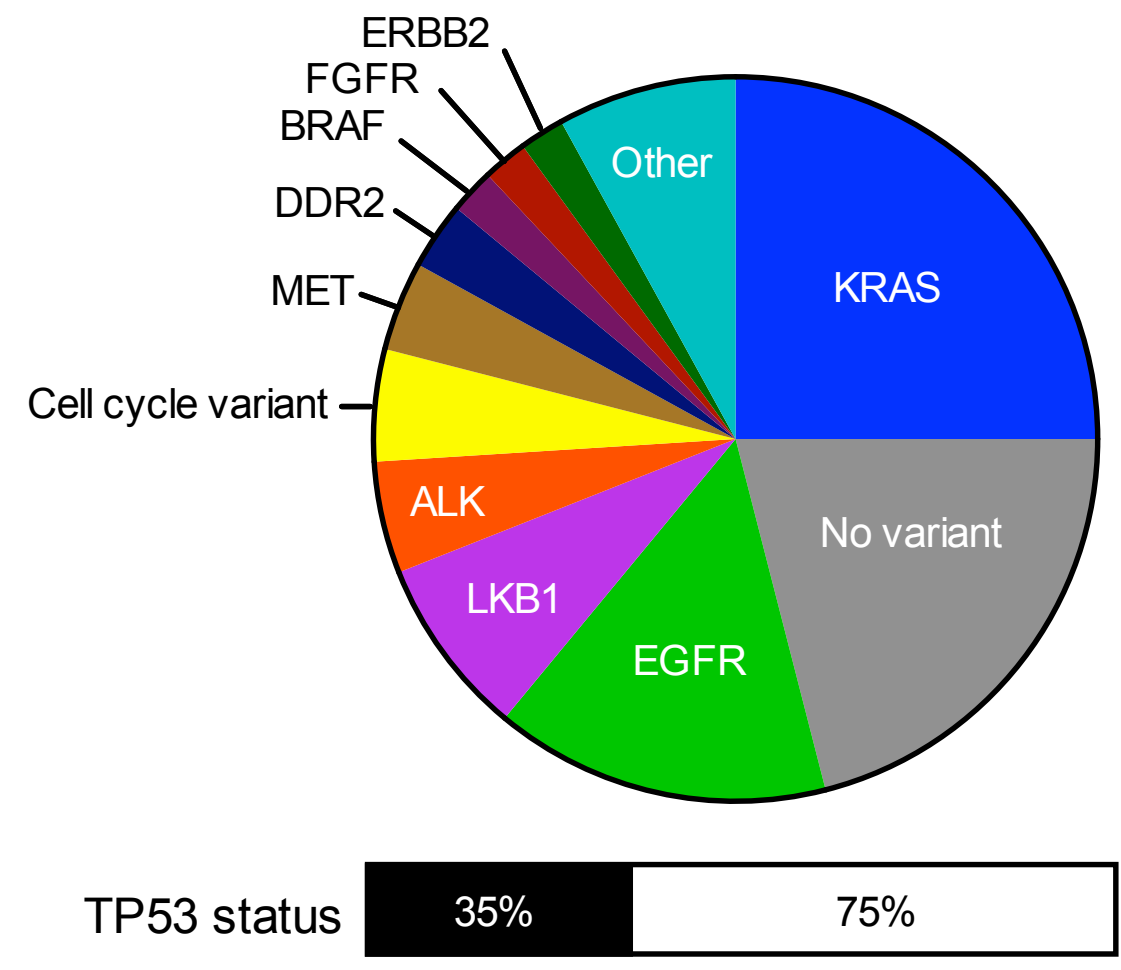

\section{Squamous Cell Carcinoma}

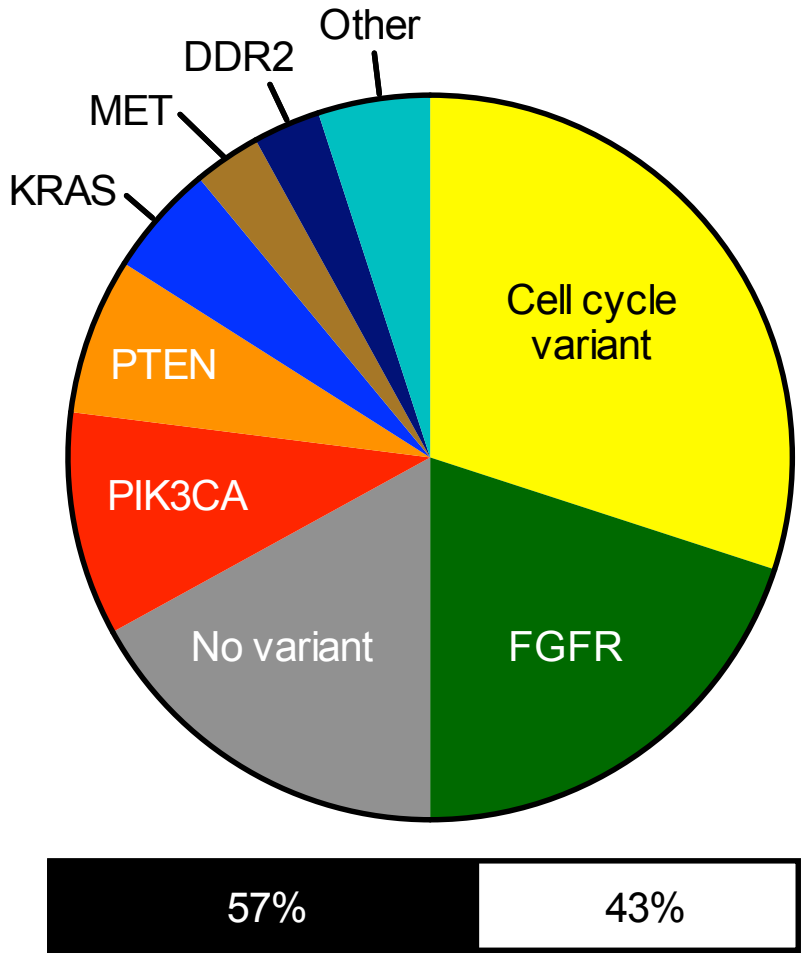

mutant 


\begin{tabular}{|l|l|l|l|l|l|}
\hline Study & Line & Phase & POM & Molecular subgroups & Location \\
\hline $\begin{array}{l}\text { National } \\
\text { Lung Matrix } \\
\text { Trial }\end{array}$ & $2^{\text {nd } \text { or later }}$ & NR Phase II & $\begin{array}{l}\text { PFS } \\
\text { ORR }\end{array}$ & $\begin{array}{l}\text { AKT, PIK3CA/PTEN, TSC, } \\
\text { LKB1, KRAS, NRAS, NF1, MET, } \\
\text { ROS1, EGFR (T790M), CCGA, } \\
\text { immunotherapy }\end{array}$ & UK \\
\hline $\begin{array}{l}\text { SAFIR_02 } \\
\text { Lung Study }\end{array}$ & $\begin{array}{l}\text { 1st line } \\
\text { maintenance }\end{array}$ & R Phase II & PFS & $\begin{array}{l}\text { mTOR, AKT, FGFR, HER2, } \\
\text { EGFR, MEK, immunotherapy }\end{array}$ & France \\
\hline Lung MAP & $\begin{array}{l}2^{\text {nd }} \text { or later } \\
\text { (SCC) }\end{array}$ & NR Phase II & $\begin{array}{l}\text { PFS } \\
\text { ORR }\end{array}$ & $\begin{array}{l}\text { PIK3CA, FGFR, CCGA, } \\
\text { immunotherapy }\end{array}$ & USA \\
\hline Darwin I/II & $1^{\text {st } \text { or later }}$ & NR Phase II & PFS & $\begin{array}{l}\text { EGFR, HER2, ALK, RET, BRAF, } \\
\text { immunotherapy }\end{array}$ & UK \\
\hline
\end{tabular}

